\title{
Description of a new genus and three new species of the family Palpimanidae (Arachnida, Araneae) from Kenya
}

\author{
Ambata D. Oketch ${ }^{1,2,3}$, Sergei Zonstein ${ }^{4,5}$, Esther N. Kioko², Shuqiang Li ${ }^{1,3}$ \\ I Institute of Zoology, Chinese Academy of Sciences, Beijing 100101, China 2 National Museums of Kenya, \\ Museum Hill, P.O. Box 40658-00100, Nairobi, Kenya 3 University of Chinese Academy of Sciences, Beijing \\ 100049, China 4 Tel Aviv University, Steinhardt Museum of Natural History, Tel Aviv 69978, Israel 5 De- \\ partment of Zoology and Centre for Invasion Biology, University of Venda, Thohoyandou, 0950, South Africa \\ Corresponding author: Shuqiang Li (lisq@ioz.ac.cn) \\ Academic editor: Galina N. Azarkina | Received 7 May 2020 | Accepted 6 July 2020 | Published 28 July 2020 \\ http://zoobank.org/E63F61C8-1E75-48C7-ABDB-242FC9B0A0C4 \\ Citation: Oketch AD, Zonstein S, Kioko EN, Li S (2020) Description of a new genus and three new species of the \\ family Palpimanidae (Arachnida, Araneae) from Kenya. African Invertebrates 61(2): 93-106. https://doi.org/10.3897/ \\ AfrInvertebr.61.54004
}

\begin{abstract}
A new genus and three new species of the spider family Palpimanidae Thorell, 1870 from Kenya are described. Sceliscelis Oketch \& Li, gen. nov. is close to Sarascelis Simon, 1887 and Scelidocteus Simon, 1907 but differs in the structure of the male palp. The new species reported are Sceliscelis marshi Oketch \& Li, sp. nov., Scelidocteus taitave Oketch \& Li, sp. nov., and Hybosida machondogo Oketch \& Li, sp. nov. Sceliscelis marshi sp. nov. is described from males and females collected from Tsavo in south Kenya. Scelidocteus taitave sp. nov. can be distinguished from other congeners, as well as from the morphologically similar Scelidomachus socotranus Pocock, 1899, by the shape of the palpal "conductor". Hybosida machondogo sp. nov. differs from other six-eyed Hybosida spp. by possessing rudimentary posterior median eyes.
\end{abstract}

\section{Keywords}

Afrotropical, Chediminae, genus, species, taxonomy

Copyright Ambata D. Oketch et al.This is an open access article distributed under the terms of the Creative Commons Attribution License (CC BY 4.0), which permits unrestricted use, distribution, and reproduction in any medium, provided the original author and source are credited. 


\section{Introduction}

Palpimanidae Thorell, 1870 is a small family of araneophagous spiders recognized by the coriaceous carapace, haplogyne genitalia, two spinnerets and especially by the first pair of legs with dorsally enlarged femora and well-developed prolateral scopula on the tibia, metatarsus and tarsus. A total of 152 species in 18 genera are distributed in tropical and subtropical zones worldwide, absent only in the Nearctic and Australia (Li 2020). Within Africa, the family is known to include 56 species belonging to 12 genera (WSC 2020), although some of these species are certainly misplaced in the family (Zonstein and Marusik 2013; Zonstein et al. 2018).

More than 800 spider species and subspecies belonging to 55 families are known from Kenya (WSC 2020). However, Palpimanidae have not been thoroughly studied. Up to now, only three species have been described: Scelidocteus incisus Tullgren, 1910, Hybosida lesserti Berland, 1920 and H. scabra Simon \& Fage, 1922. In this paper, one new genus and three new species of palpimanid spiders found during the examination of spiders collected in various protected sites in Kenya are described.

\section{Materials and methods}

All spiders were preserved in 95\% alcohol. Specimens were examined and measured using a LEICA M205C stereomicroscope. Images were captured using an Olympus C7070 wide zoom digital camera mounted on an Olympus SZX12 dissecting microscope or on an Olympus BX51 compound microscope. Male and female copulatory organs were dissected, and the specimens were then photographed on glass slides fitted with cotton wool to ensure a white, uniform background. Digital images were prepared using Helicon Focus version 6.0 image stacking software and then edited using Adobe Photoshop CS4 version 11.0.0.

Leg lengths and palp segments are given in the following sequence: total (femur, patella, tibia, metatarsus, tarsus). Internal structures of the genitalia were illustrated after being cleared in lactic acid, then placed in alcohol for a few minutes. Measurements are given in millimeters. Holotypes and paratypes are deposited in the National Museums of Kenya (NMK), Nairobi, Kenya.

Abbreviations. AER - anterior eye row, ALE - anterior lateral eyes, am - accompanying membrane, AME - anterior median eyes, co - "conductor", ch - receptive chamber, cy - cymbium, ds - dorsal portion of scutum, em - embolus, $\mathrm{Ft}$ - fine threads, Gr - grape-shaped glands, hle - hook-like extension, MOQ - median ocular quadrangle, pe - palm-like embolic extension, PER - posterior eye row, PLE - posterior lateral eyes, PME - posterior median eyes, Re - rigid extensions of posterior wall of epigastric fold, $\mathrm{rt}$ - retrolateral thorn, sco - scopula, $\mathrm{Sr}-\mathrm{sac}-$ like receptacle. 


\section{Taxonomy}

\section{Family Palpimanidae Thorell, 1870 \\ Subfamily Chediminae Simon, 1893}

\section{Sceliscelis Oketch \& Li, gen. nov.}

http://zoobank.org/9F855192-68DE-4B2C-8324-804D599234C4

\section{Type species. Sceliscelis marshi sp. nov.}

Etymology. This genus possesses some characteristics that are also found in Sarascelis Simon, 1887 and Scelidocteus Simon, 1887, such as the dentate segments of leg I (which include at least the dorsal surface of the coxa and basal part of the femur) and the spiral embolus. The name is a combination of "Sceli" from Scelidocteus and "Scelis" from Sarascelis. The gender is feminine.

Diagnosis. The new genus closely resembles Sarascelis in general appearance by having much larger AMEs (Fig. 1A; also see Jézéquel 1964, fig. 5a-c, Zonstein and Marusik 2013; figs 5, 6). It can, however, be distinguished from Sarascelis, Scelidocteus and the close ally Steriphopus Simon, 1887 by (1) having a greatly extended bulb (vs. the more or less bulky palpal structures of Sarascelis and Steriphopus) (2) the large AMEs (Steriphopus has considerably smaller AMEs) (3) the shape of the thoracic fovea, which is an elongated $\Omega$-shape in Sceliscelis (vs. a longitudinal slit or anchor-like in Sarascelis and Scelidocteus) (4) the presence of a hook-like extension at the distal end of a sword-like "conductor" (vs. extension absent in other members of the family) (5) the poorly developed scopula on metatarsus and tarsus I (6) the rugose carapace in Sceliscelis gen. n. (vs. smooth or finely rugose in Sarascelis, Scelidocteus and Steriphopus) (see Zonstein and Marusik 2013). Females of Sceliscelis can be distinguished from those of Sarascelis and Scelidocteus by the wavy, rigid extension of the genital area and by a pair of divergent sac-like receptacles.

Description. Medium-sized. Carapace dome shaped, coarsely granulated and hairless, medially elevated, fovea longitudinal, open posteriorly (elongated $\Omega$-shape). Eight eyes, MOQ trapezoidal; AME largest, about 3 times as large as PME; ALE, PLE and PME subequal to each other. AER straight. Labium triangular, notched, longer than wide but broader at base. Chelicerae directed ventrally, 2 times longer than clypeus, granulate. Endites trapezoidal, about 1.5 times longer than wide. Abdomen clay yellow, oval and covered with short, gray setae in both sexes. Femur of male palp slender, longer than wide, patella shorter than "conductor". Cymbium with setae, pointed at tip and indented (prolateral view). Embolus spiral, with accompanying membrane and a silvery, palm-like embolic extension. "Conductor" sword-shaped, longer than wide, slightly longer than embolus. Endogyne wavy anteriorly, forming a rigid epigastric wall.

Composition. This genus currently includes only the type species. 


\section{Sceliscelis marshi Oketch \& $\mathrm{Li}$, sp. nov.}

http://zoobank.org/01D83454-CC28-45A1-91B5-87D1424A3C6A

Figs 1, 2

Type material. Holotype ${ }^{\lambda}$, Kenya, Taita Taveta County, near Mtito Andei, Tsavo West National Park, Rhino Sanctuary, 38¹9.96'E, 03¹.230'S, 730 m, 28.VII.2016, sifting leaf litter, Grace Kioko leg. Paratype 1 , , same data as holotype.

Etymology. This species is named after Mr. Brian Marsh OBE, the founder of the Marsh Christian Trust Awards for Ecologists in Africa, which the third author was awarded in 2019; noun (name) in genitive case.

Diagnosis. See diagnosis of the genus.

Description. Male. Habitus as in Fig. 1A-C. Total body length 3.83. Color in alcohol: carapace, sternum, chelicerae, labium, leg I coxa and epigastric scutum uniformly reddish orange to reddish brown, entire palp and most of leg I slightly paler reddish orange, legs II-IV with yellowish femur and patella and darkened distal segments. Carapace 2.13 long, 1.75 wide. Fovea longitudinal, open posteriorly. Eye sizes and interdistances: AME 0.13, PME 0.05, PLE 0.06, ALE 0.06, AME-AME 0.09, PME-PME 0.19, AME-PME 0.09, AME-ALE 0.06, PME-PLE 0.13, ALE-PLE $<0.01$. AER almost straight. Labium triangular 0.25 long, 2 times the length of labium notch, clypeus 2 times shorter than length of chelicerae. Sternum 1.00 long, 0.78 wide, granulate. Endites trapezoidal, pale yellow anteriorly. Abdomen as in genus description. Palp: Patella sub-globular, as long as $1 / 3$ length of tibia. Tibia 0.35 long, 0.31 wide. Cymbium about 2 times longer than wide.

Female. Cephalothorax in dorsal and ventral aspects as in Fig. 2A, B, respectively. Color in alcohol: carapace, sternum, chelicerae, labium, leg I coxa and epigastric scutum and abdomen same as in male. Body length 5.1. Carapace 3.1 long, 2.2 wide, fairly granulate. Eye sizes and interdistances: AME 0.15, PME 0.08, PLE 0.06, ALE 0.06, AME-AME 0.09, PME-PME 0.19, AME-ALE 0.06, PME-PLE 0.13, ALE-PLE $<0.01$. Notch is approximately $1 / 2$ the length of labium which is 0.24 long. Clypeus/ chelicera length ratio 1:1. Epigastric scutum sclerotized, book lung operculum visible, lateral sclerites present, posterior edge strongly undulate. Vulva not visible through integument, distant from epigastric fold, with stalked grape-shaped glands. Receptacles oval, mounted on a pair of irregular receptive chambers, separated (Fig. 2C, D). Leg and palp measurements in Table 1.

Distribution. This species is currently known only from the type locality.

Table I. Type male (female) leg and palp measurements.

\begin{tabular}{lcccccc}
\hline & Femur & Patella & Tibia & Metatarsus & Tarsus & Total \\
\hline Palp & $0.91(0.85)$ & $0.15(0.13)$ & $0.35(0.37)$ & - & $0.50(0.42)$ & $1.91(1.77)$ \\
I & $0.85(0.94)$ & $0.94(0.80)$ & $0.70(0.75)$ & $0.30(0.25)$ & $0.31(0.22)$ & $3.10(2.96)$ \\
II & $1.00(0.69)$ & $0.50(0.50)$ & $0.65(0.63)$ & $0.50(0.38)$ & $0.32(0.31)$ & $2.97(2.51)$ \\
III & $0.63(0.52)$ & $0.50(0.41)$ & $0.50(0.50)$ & $0.35(0.47)$ & $0.24(0.22)$ & $2.22(2.51)$ \\
IV & $1.25(0.78)$ & $0.30(0.50)$ & $0.88(0.81)$ & $0.75(0.56)$ & $0.25(0.25)$ & $3.31(2.90)$ \\
\hline
\end{tabular}




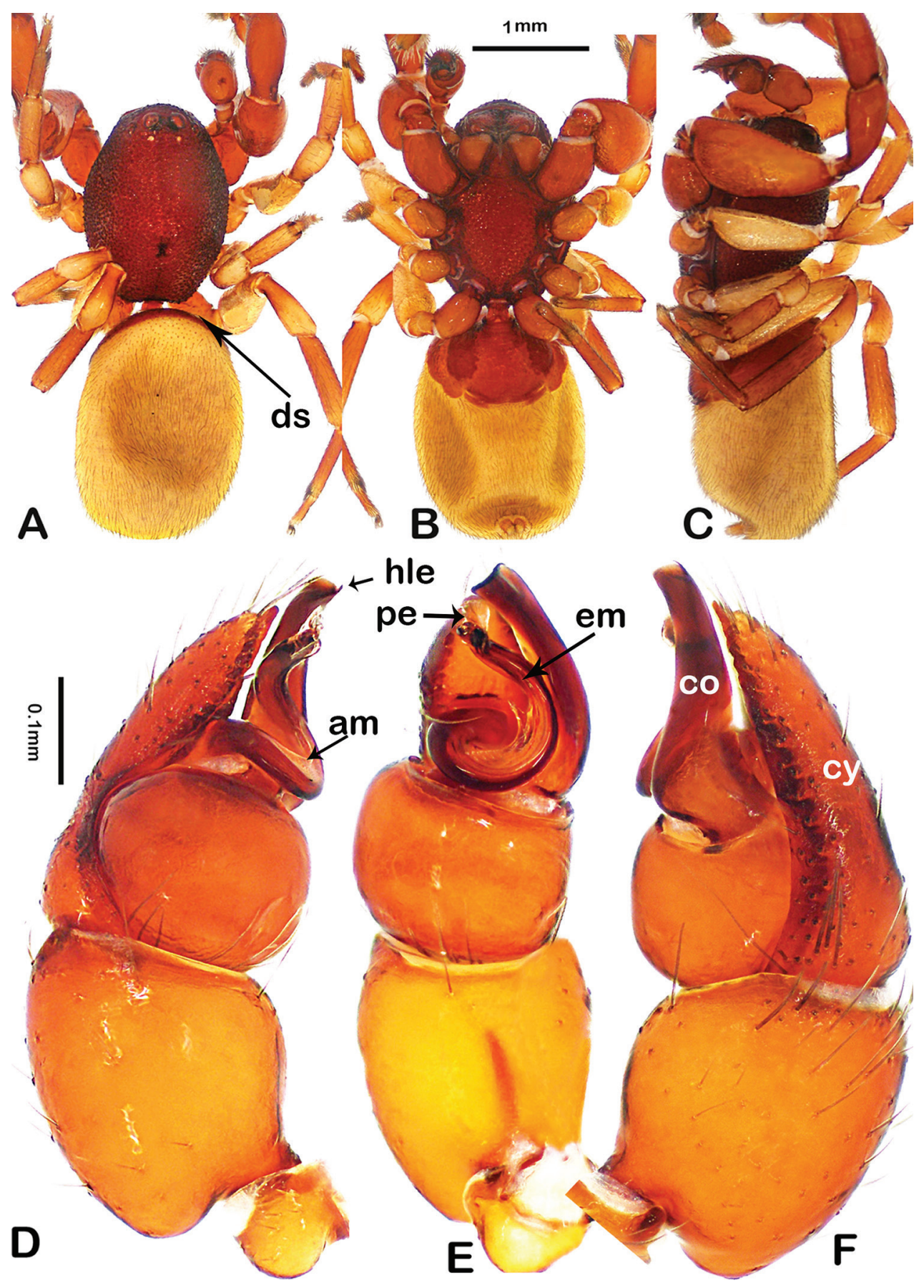

Figure I. Sceliscelis marshi sp. nov., male holotype A-C habitus in dorsal, ventral and lateral aspects D-F palp: $\mathbf{D}$ prolateral $\mathbf{E}$ ventral and $\mathbf{F}$ retrolateral aspects. Abbreviations: am-accompanying membrane, co - "conductor," cy - cymbium, ds - dorsal portion of scutum, em - embolus, hle - hook-like extension, pe - palm-like embolic extension. Scale bars: $1 \mathrm{~mm}(\mathbf{A}-\mathbf{C}), 0.1 \mathrm{~mm}(\mathbf{D}-\mathbf{F})$. 


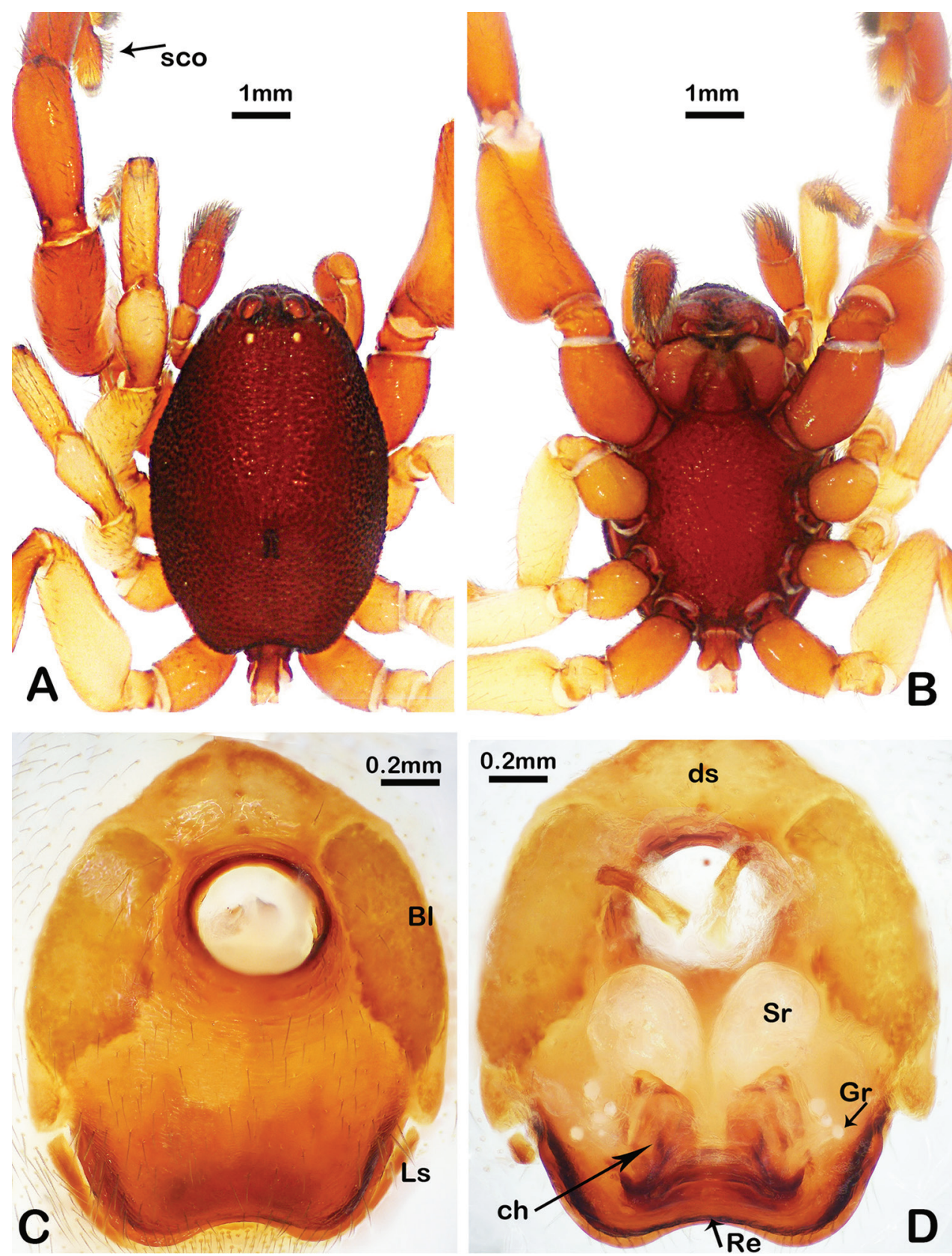

Figure 2. Sceliscelis marshi sp. nov., female paratype. Cephalothorax $\mathbf{A}$ dorsal and $\mathbf{B}$ ventral aspects C, D endogyne, ventral and dorsal aspects, respectively. Abbreviations: $\mathrm{Bl}$ - book lung operculum, ch - receptive chamber, ds - dorsal portion of scutum, Gr - grape-shaped glands, Ls - lateral sclerite, $\mathrm{Re}-$ rigid extension of posterior wall of epigastric fold, sco - scopula, $\mathrm{Sr}-$ sac like receptacle. Scale bars: $1 \mathrm{~mm}(\mathbf{A}, \mathbf{B}), 0.2 \mathrm{~mm}(\mathbf{C}, \mathbf{D})$. 


\section{Genus Scelidocteus Simon, 1907}

Type species. Scelidocteus pachypus Simon, 1907, by subsequent designation.

Notes. All seven described species of this genus are endemic to Africa, the majority of them in West and Central African countries. Scelidocteus taitave sp. nov. is the first species to be recorded from Kenya and East Africa (WSC 2020). Scelidocteus resembles Scelidomachus and Chedima Simon, 1873 in general appearance, especially in having an anteriorly blunt (not rounded) carapace with pronounced, obtuse anterolateral corners, but can be distinguished from Chedima by the uniformly colored abdomen (vs. spotted) with short gray setae and the eye shape and arrangement (MOQ in Chedima is longer than wide, whereas it is subquadrate in Scelidocteus).

\section{Scelidocteus taitave Oketch \& Li, sp. nov.} http://zoobank.org/DE20171E-AD59-4DFF-901B-9B139F91DC5F

Figs 3, 4

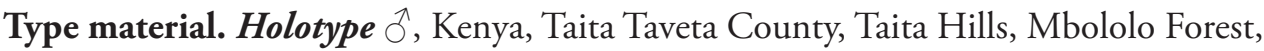
$30^{\circ} 26.85^{\prime}$ E, 03⒛36'S, 1631 m, 2.VIII.2018, Ambata Oketch leg. Paratypes 1 गे, 2 + , same data as holotype.

Etymology. The specific name is a combination of Taita and Taveta, the county from which the specimens were collected; noun in apposition.

Diagnosis. Males of this species differ from those of other members of Scelidocteus by the uniquely spiral-shaped embolus (Fig. 3C-E cf. Pocock 1903, fig. 3; de Lessert 1930, fig. 4; Jézéquel 1964, figs 2A, B, 4a, b). Females of $S$. taitave sp. nov. differ from those of other species by the structure of the endogyne; the orientation of sac-like receptacles (touching medially, with a space below them) mounted on oval, membranous receptive chambers and the outline of a rigid extension of the posterior wall of the epigastric fold (Fig. 4C, D; Jézéquel 1964, figs 1, 3).

Description. Male. Fig. 3A, B. Total body length 3.90. Color in alcohol: carapace and chelicerae orange-red, legs I, endites, sternum and labium orange, legs II-IV lighter, yellowish. Carapace 1.88 long, 1.50 wide at leg II, oval in dorsal view, finely granulate, cephalic part slightly elevated behind eye area. Thoracic fovea a longitudinal, deep slit, approximately 0.10 long. Eye sizes and interdistances: AME 0.13, ALE 0.06, PLE 0.06, PME 0.06, AME-AME 0.05, AME-ALE 0.08, PME-PME 0.09, AMEPLE 0.04, ALE-PLE <0.01, PLE-PME 0.24. AER slightly procurved, almost straight, PER strongly recurved. Chelicerae flattened anteriorly towards the fangs, 1.60 long, cheliceral furrow with several peg-like teeth. Stridulatory mound absent. Clypeus approximately 2 times shorter than length of chelicerae. Sternum 1.09 long, 0.86 wide at leg II; shield shaped, rebordered, finely granulate. Endites almost D-shaped, labium notch 0.13 long, about a quarter of labium length. Leg I: coxa, patella and tibia pos- 


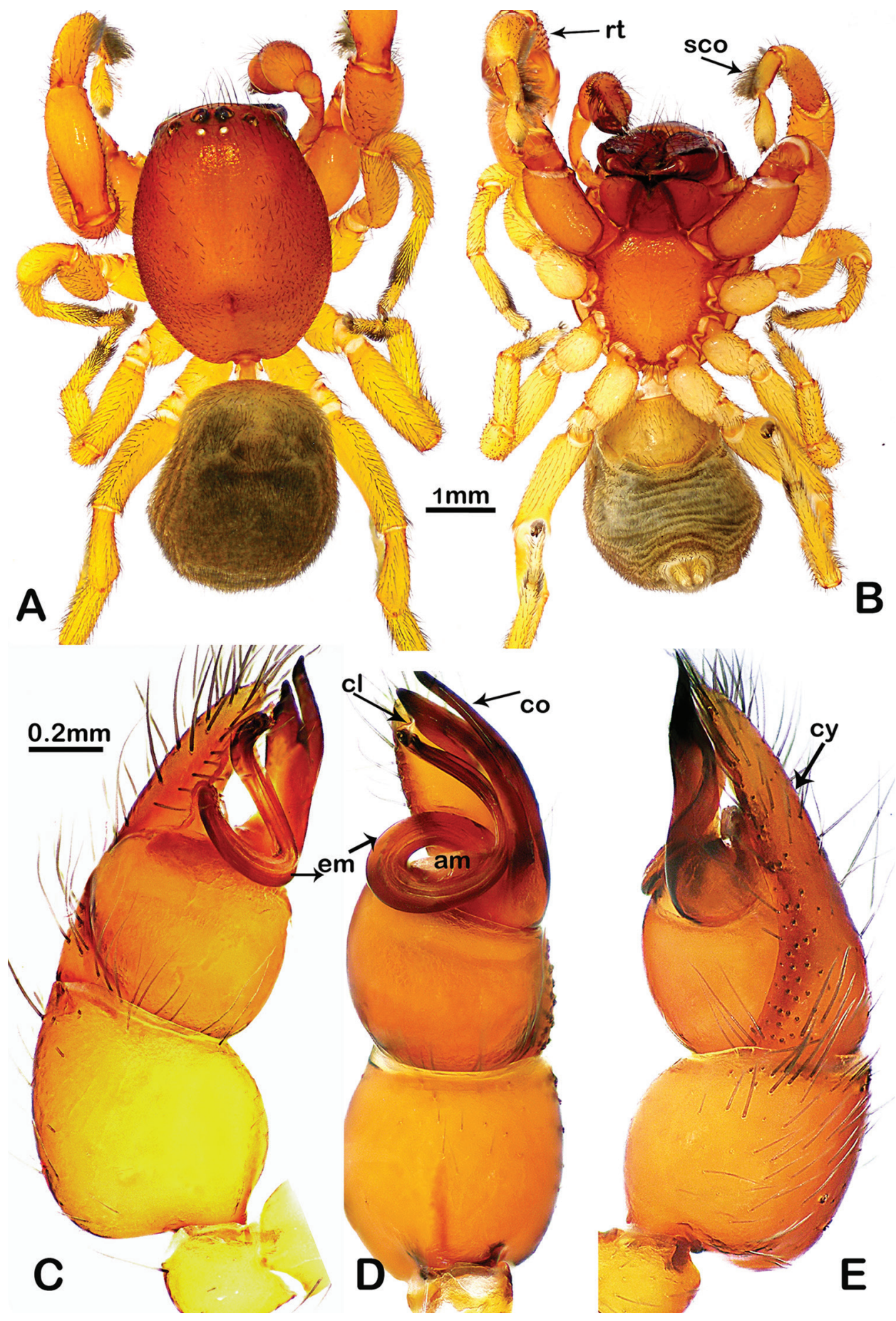

Figure 3. Scelidocteus taitave sp. nov., male holotype A, B dorsal and ventral habitus respectively C-E palp: C prolateral $\mathbf{D}$ ventral $\mathbf{E}$ retrolateral aspects. Abbreviations: am - accompanying membrane, cl - claw like extension, co - "conductor", em - embolus, cy - cymbium rt - retrolateral thorns, sco scopula. Scale bars: $1 \mathrm{~mm}(\mathbf{A}, \mathbf{B}), 0.2 \mathrm{~mm}(\mathbf{C}-\mathbf{E})$. 

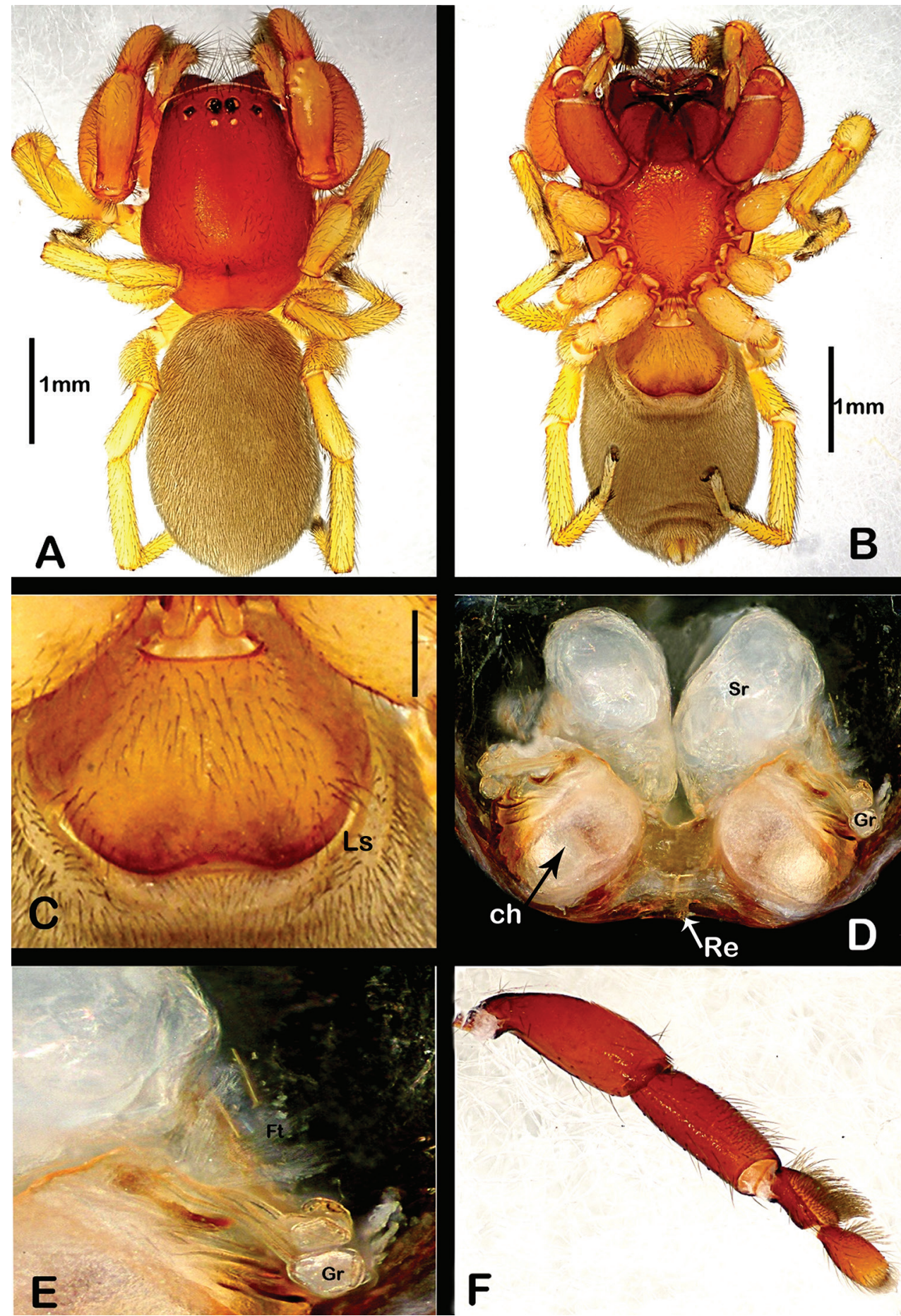

Figure 4. Scelidocteus taitave sp. nov., female paratype A, B habitus $\mathbf{C}$ endogyne ventral $\mathbf{D}$ same, ventral $\mathbf{E}$ same, enlarged $\mathbf{F}$ leg I. Abbreviations: ch - receptive chamber, Ft - fine threads, Gr - grape-shaped glands, $\mathrm{Re}$ - rigid extensions of posterior wall of epigastric fold, $\mathrm{Sr}-$ sac like receptacle. Scale bars: $1 \mathrm{~mm}(\mathbf{A}, \mathbf{B})$. 
Table 2. Type male (female) palp and leg measurements.

\begin{tabular}{lcccccc}
\hline & Femur & Patella & Tibia & Metatarsus & Tarsus & Total \\
\hline Palp & $0.66(0.61)$ & $0.24(0.21)$ & $0.38(0.37)$ & - & $0.35(0.39)$ & $1.63(1.58)$ \\
I & $1.38(1.41)$ & $0.65(0.81)$ & $1.00(1.09)$ & $0.38(0.38)$ & $0.40(0.38)$ & $3.81(4.07)$ \\
II & $0.88(0.85)$ & $0.69(0.70)$ & $0.80(0.80)$ & $0.50(0.41)$ & $0.40(0.28)$ & $3.27(3.04)$ \\
III & $0.90(1.00)$ & $0.60(0.75)$ & $0.60(0.69)$ & $0.60(0.74)$ & $0.40(0.44)$ & $3.10(3.62)$ \\
IV & $0.90(1.38)$ & $0.80(0.80)$ & $0.90(1.00)$ & $0.84(1.00)$ & $0.40(0.50)$ & $3.84(4.68)$ \\
\hline
\end{tabular}

sess dark, thorn-like outgrowths and well developed prolateral scopula on tibia and metatarsus. Tarsus I with weakly developed scopula. Leg and palp measurements as in Table 2. Abdomen oval with short, grey setae, dorsal portion of epigastric scutum very small, pedicel short, spinnerets short and unsegmented. Palp (Fig. 3C-E): tibia, as long as wide, approximately 2.5 times wider than femur. Cymbium long and thin, tapering distally. "Conductor" bifurcate; embolus long and spiral, obscuring some parts of tegulum. Embolus ends with a bleached, claw-like structure at apex.

Female. General appearance as in Fig. 4A, B. Coloration as in male. Total length 4.88. Carapace 2.19 long, 1.72 wide. Eye sizes and interdistances: AME 0.13, ALE 0.06, PLE 0.06, PME 0.06, AME-AME 0.05, ALE-AME 0.08, ALE-PLE < 0.01, PLE-PME 0.20, PME-PME 0.7. Sternum 1.25 long, 1.00 wide, labium 0.5 long, 0.44 wide at the base, labium notch $1 / 3$ length of labium. Vulva with fine, thread-like structures and 3 pairs of stalked, grape-shaped glands attached to a pair of relatively ovate and membranous receptive chambers.

Distribution. This species is currently known only from the type locality.

\section{Genus Hybosida Simon, 1898}

Type species. Hybosida lucida Simon, 1898, by monotypy.

Diagnosis. All four described species of this genus have six eyes, PMEs are absent (Simon 1898, Platnick 1979, Saaristo 2010). H. dauban Platnick, 1979 and H. lucida Simon, 1898 are endemic to Seychelles and H. scabra and H. lesserti are known from East Africa.

\section{Hybosida machondogo Oketch \& Li, sp. nov.} http://zoobank.org/D4F9BC3A-3196-498E-89F0-F0750B28A377

Figs 5, 6

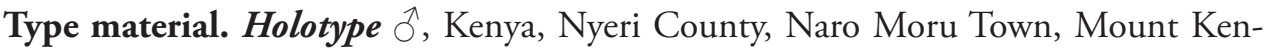
ya National Park, Naro Moru Gate, Forest Valley, 37²10.16'E, 00¹0.61'S, 2488 m, 25.VII.2017, Grace Kioko leg.

Other material examined. 2 s subadults, Kenya, Uasin Gishu County, Endebbes Town, Mount Elgon National Park, Mutamaiyo Camp Site, 34²43.07'E, $01^{\circ} 4.02^{\prime} \mathrm{N}$, 2824 m, 7.VII.2017, Grace Kioko leg. 

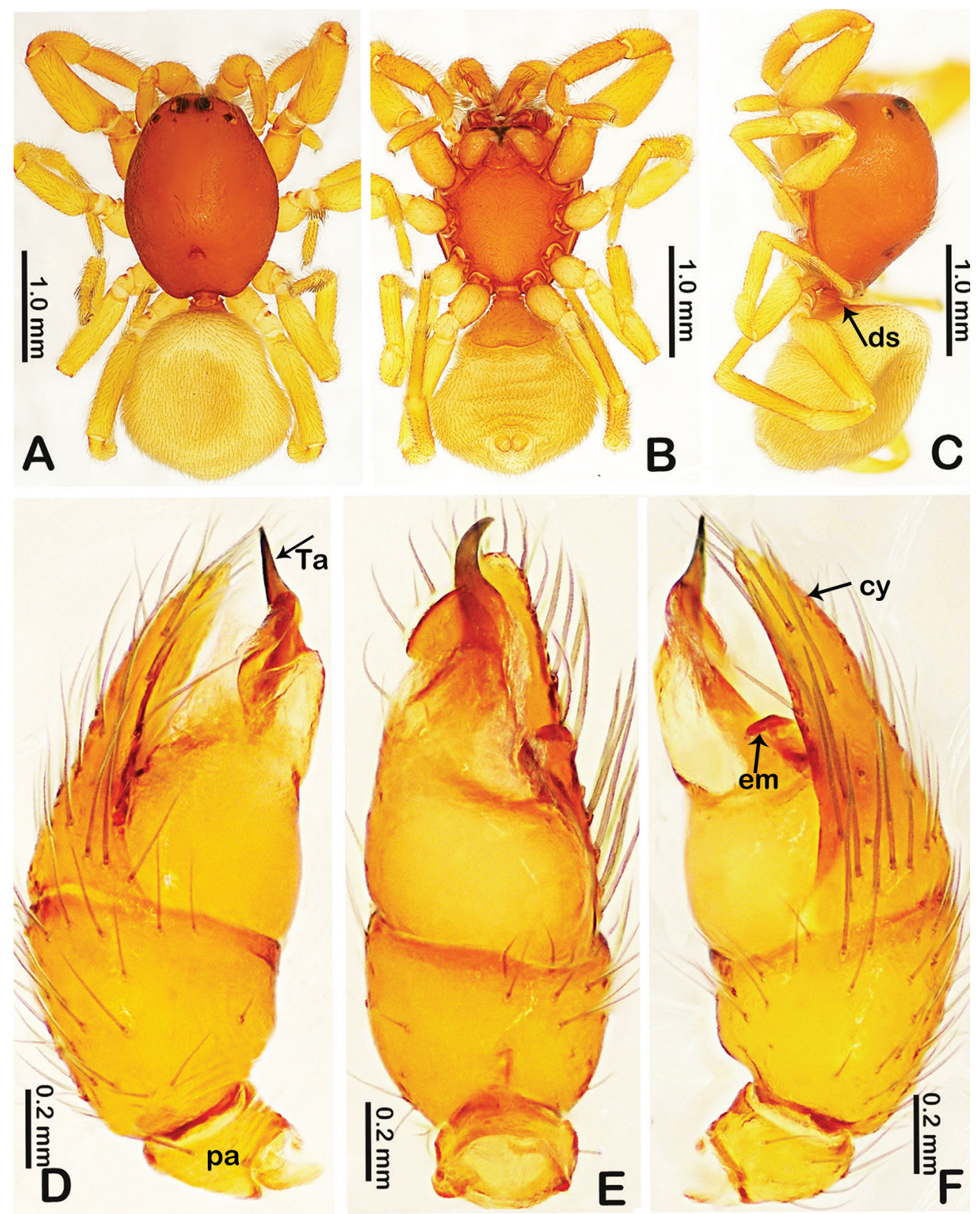

Figure 5. Hybosida machondogo sp. nov. male holotype $\mathbf{A}-\mathbf{C}$ habitus: $\mathbf{A}$ dorsal $\mathbf{B}$ ventral and $\mathbf{C}$ prolateral aspects) D-F palp: D prolateral $\mathbf{E}$ ventral $\mathbf{F}$ retrolateral. Scale bars: $1 \mathrm{~mm}(\mathbf{A}-\mathbf{C}), 0.2 \mathrm{~mm}(\mathbf{D}-\mathbf{F})$. Abbreviations: cy - cymbium, ds - dorsal portion of scutum, em - embolus, pa - patella, Ta - tegula apophysis.

Etymology. The specific name is a combination of two Swahili words "macho", meaning eyes, and "ndogo", meaning small, referring to the indiscernible posterior median eyes of this species. 

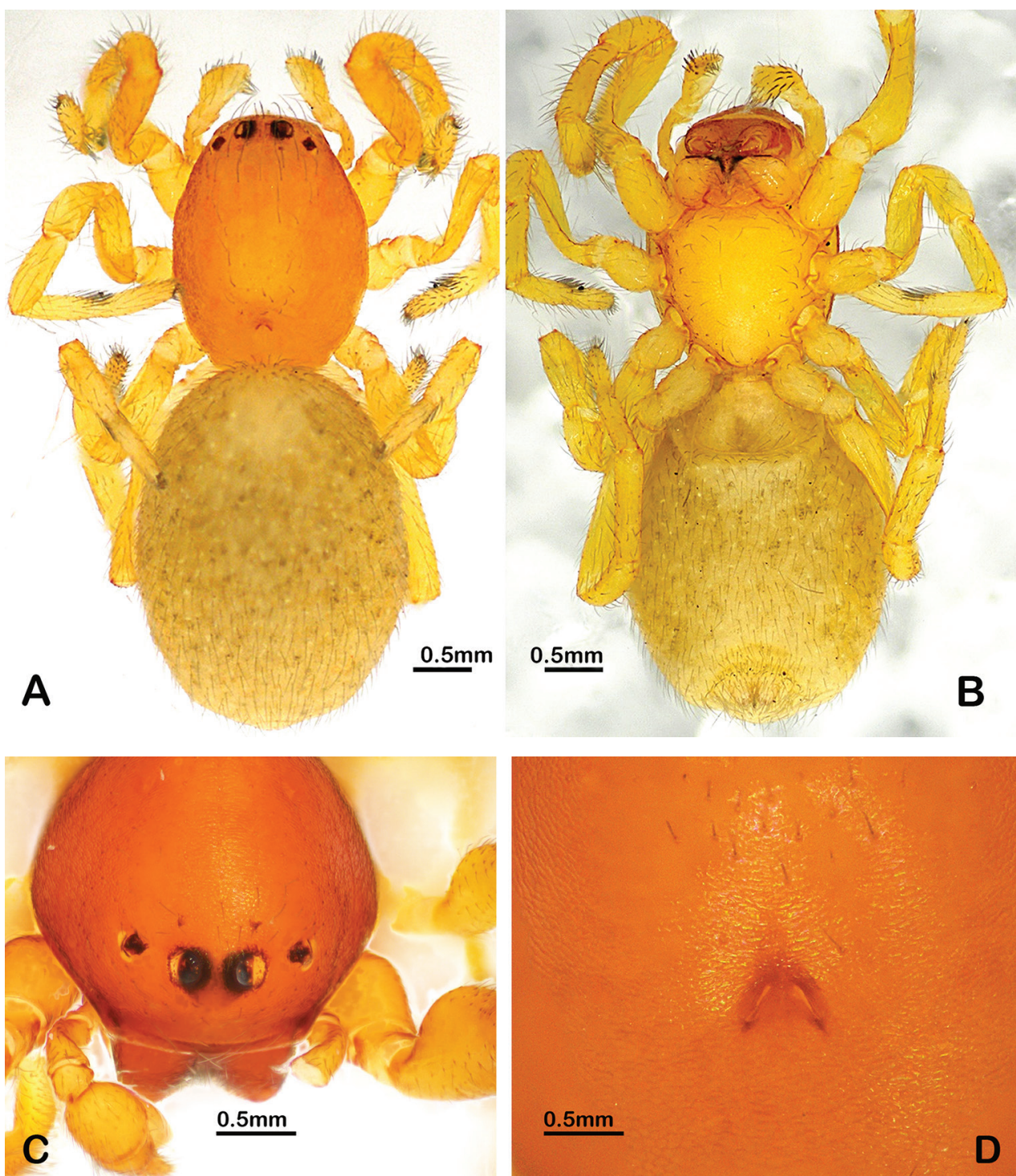

$0.5 \mathrm{~mm}$

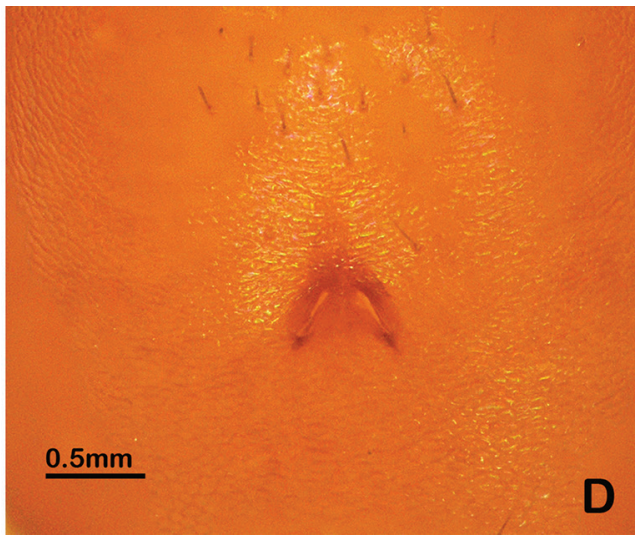

Figure 6. Hybosida machondogo sp. nov., subadult male, habitus $\mathbf{A}$ dorsal view $\mathbf{B}$ ventral $\mathbf{C}$ male holotype, ocular area, anterodorsal $\mathbf{D}$ thoracic fovea, dorsal. Scale bars: $0.5 \mathrm{~mm}$ (A-D).

Diagnosis. Like other members of Chediminae, Hybosida machondogo sp. nov. possess contiguous lateral eyes and accessory structures of the male palp (see Zonstein and Marusik 2013, figs 1-9; Zonstein et al. 2018). It closely resembles H. lesserti by having (1) a more compact carapace with the cephalic part narrowed (2) an elevated carapace with a steep posterior slope (3) a strongly convex carapace in lateral view and 
(4) poorly developed scopula on both the metatarsi and tarsi of legs I (see Berland 1920, figs 128, 131). However, $H$. machondogo sp. nov. differs from $H$. lesserti and other members of this genus by having (1) 8 eyes instead of 6, (2) a bulb with relatively long, sharp and less curved apophysis (vs. strongly curved in H. lesserti).

Description. Male. Fig. 5A-C. Total body length 2.05. Carapace, pedicel and sternum reddish orange, 1.11 long, 0.83 wide at leg II, carapace dome-shaped and covered with white setae at the edges, finely rugose. Thoracic region higher than cephalic region, steeply sloping towards pedicel (Fig. 5C). Fovea crescent-like, bipartite (Figs 5A, 6D), wide distally (sulci diverging). Sternum with long, gray setae. Eyes: AER strongly recurved, PER slightly procurved (Fig. 6C). Eye sizes and interdistances: AME 0.09, PME $\leq$ 0.01, PLE=ALE=0.04, AME-AME 0.05, AME-ALE 0.08, AME-PLE 0.06, PME-PME 0.09. Clypeus about 2 times higher than diameter of AME. Labium deeply notched (smoothly recurved in all described palpimanids). Endites colored as sternum, depressed proximally, covered with gray setae. Legs: yellowish without spines. Femur I enlarged and longer than patella; scopula on tibia, metatarsus and tarsus weakly developed (compared to Scelidocteus). Femur II somewhat longer than femora III-IV (Fig. 5C), tarsal claws long and unidentate. Metatarsi II-IV with distal preening comb. Generally, leg integument appears rough. Leg and palp measurements as in Table 3. Abdomen: unsclerotized, uniformly yellowish, oval, narrow towards the pedicel and wide at the middle. Pedicel considerably exposed, lateral and postgastric scutum extensions absent, dorsal portion of scutum present but short. Spinnerets short yellowish and unsegmented.

Palp yellowish, femur longer than tibia, patella about 2 times shorter than femur. Tibia enlarged, almost conical in prolateral view, 1.86 times wider than patella, about 2 times wider than femur. Cymbium about 1.5 times longer than tibia, slightly shorter than apophysis. Tegular region is membranous, apophysis pointed, extends anteriorly. Embolus short, blunt and directed laterally (Fig. 5D-F).

Female. Unknown.

Distribution. This species is currently known only from the type locality.

Notes. This species is peculiar because it is at odds with the initial description of the type species of the genus Hybosida, which states that the number of eyes is 6 . It does, however, resemble Hybosida in the shape of the carapace, the fovea and the general structure of the male palp. It is therefore treated as belonging to this genus.

Table 3. Male palp and leg measurements.

\begin{tabular}{lcccccc}
\hline & Femur & Patella & Tibia & Metatarsus & Tarsus & Total \\
\hline Palp & 0.60 & 0.24 & 0.38 & - & 0.29 & 1.51 \\
I & 0.80 & 0.55 & 0.45 & 0.25 & 0.30 & 2.35 \\
II & 0.60 & 0.30 & 0.45 & 0.35 & 0.35 & 2.05 \\
III & 0.55 & 0.30 & 0.45 & 0.40 & 0.30 & 2.00 \\
IV & 0.60 & 0.30 & 0.65 & 0.50 & 0.35 & 2.40 \\
\hline
\end{tabular}




\section{Acknowledgements}

The manuscript benefited greatly from comments by Galina N. Azarkina, Yuri Marusik and Yanfeng Tong. The English was kindly checked by Sarah Crews (USA). The fieldwork was facilitated by Kenya Wildlife Service (KWS), Kenya Forest Service (KFS), National Environment Management Authority (NEMA) and the National Commission for Science, Technology and Innovation (NACOSTI). The study was financially supported by the National Natural Science Foundation of China to Shuqiang Li (NSFC-31530067).

\section{References}

Berland L (1920) Araneae (2e partie). Voyage de Ch. Alluaud et R. Jeannel en Afrique Orientale (1911-1912): Résultats scientifiques: Arachnida. Paris 4, 95-180.

Jézéquel JF (1964) Araignées de la savane de Singrobo (Côte d'Ivoire). II. Palpimanidae et Zodariidae. Bulletin du Muséum National d'Histoire Naturelle 36: 326-338.

Lessert R de (1930) Araignées du Congo recueillies au cours de l'expédition organisée par l'American Museum (1909-1915). Quatrième et dernière partie. Revue Suisse de Zoologie 37: 613-672. https://doi.org/10.5962/bhl.part.117639

Li S (2020) Spider taxonomy for an advanced China. Zoological Systematics 45(2): 73-77. https://doi.org/10.11865/zs.202011

Platnick NI (1979) Contributions à l'étude de la faune terrestre des îles granitiques de l'archipel des Séchelles (Mission P.L.G. Benoit - J.J. Van Mol 1972). Araneae: Palpimanidae. Revue Zoologique Africaine 93: 461-466.

Pocock RI (1903) Arachnida. In: Forbes HO (Ed.) The Natural History of Sokotra and Abdel-Kuri. Special Bulletin of the Liverpool Museum, 175-208.

Saaristo MI (2010) Araneae. In: Gerlach J, Marusik YM (Eds) Arachnida and Myriapoda of the Seychelles Islands. Siri Scientific Press, Manchester, 8-306.

Simon E (1898) Etudes arachnologiques. 29e Mémoire. XLVI. Arachnides recueillis en 1895 par M. le Dr A. Brauer (de l'Université de Marburg) aux îles Séchelles. Annales de la Société Entomologique de France 66: 370-388.

WSC (2020) World Spider Catalog. Version 21.0. Natural History Museum Bern. https://doi. org/10.24436/2 [accessed on 27.03.2020]

Zonstein SL, Marusik YM (2013) On Levymanus, a remarkable new spider genus from Israel, with notes on the Chediminae (Araneae, Palpimanidae). ZooKeys 326: 27-45. https://doi. org/10.3897/zookeys.326.5344

Zonstein SL, Marusik YM, Omelko MM (2018) Redescription of the monotypic genus Scelidomachus Pocock, 1899 (Aranei: Palpimanidae) and its type specie. Arthropoda Selecta 27(1): 53-56. https://doi.org/10.15298/arthsel.27.1.07 